\section{QIJEI}

International Journal for

Educational Integrity

\title{
Editorial, Volume 10(1): Special Issue
}

Welcome to a Special Issue of the International Journal for Educational Integrity: Best papers from the Plagiarism Across Europe and Beyond Conference, Brno, Czech Republic, 12-13 June 2013. The IJEI acknowledges the generous collaboration and collegial support of the organisers of the conference, particularly Tomas Foltýnek (Conference Convenor) and Irene Glendinning, Project Leader of the Impact of Policies for Plagiarism in Higher Education across Europe Project (IPPHEAE). Selected 'best papers' were submitted to the IJEI for consideration and additional double-blind peer review. As a result of subsequent revisions, the papers in this issue are substantially different from the original versions presented at the Czech conference.

We open the issue with an overview and summary of results from the IPPHEAE by Project Leader Irene Glendinning from Coventry University, UK. Funded by the European Commission (2010-2013), the IPPHEAE is possibly the broadest study of academic integrity in Europe ever conducted, with a comparative study of academic integrity policies and procedures in higher education institutions (HEls) across 27 European Union member states.

The project used online questionnaires, student focus groups, structured interviews and analysis of documentary evidence to determine how well institutional procedures were understood, to what extent they were operating as intended and whether there was consistency of outcomes within and between institutions. Almost 5,000 responses were received in 14 different languages. Participants included students (at undergraduate and masters' levels), teaching staff and senior managers.

Glendinning presents results from the survey that focused specifically on institutional policies and highlights examples of good practice as well as areas of concern. In keeping with international research from other settings and locations, the IPPHEAE findings indicate that there is no 'one size fits all' approach to academic integrity policy and practice. Each country and indeed each HEI needs to develop a tailored approach according to individual context, and taking into account the maturity of existing policies and systems.

IPPHEAE project partners Tomáš Foltýnek and Jiří Rybička from Mendel University, Czech Republic, and Catherine Demoliou from the University of Nicosia, Cyprus, use data obtained from the project survey to address the question: 'Do students think what teachers think about plagiarism?'. The researchers compare and contrast the overall data on students' and teachers' attitudes to academic writing, their perceptions of plagiarism and plagiarism penalties, and their knowledge of institutional policies/ procedures on plagiarism. Results indicate that there is a discrepancy in understanding between these two key stakeholder groups relating to how students learn about academic integrity, the challenges of academic writing, the causes of student plagiarism, identifying plagiarism, appropriate penalties for plagiarism, and knowledge of institutional policy. The authors contend that teachers' attitudes may require reflection and realignment to ensure they have a better understanding of students' educational needs and perceptions of plagiarism so that appropriate support can be offered.

In the third paper, Rui Sousa-Silva from Universidade do Porto, Portugal, uses a forensic linguistics approach to analyse real-life plagiarism cases by higher education students. The author compares suspected plagiarised strings of text against the most

The International Journal for Educational Integrity is available online at:

http://www.ojs.unisa.edu.au/journals/index.php/IJEI/

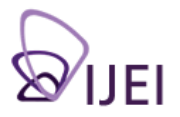


likely original text, and demonstrates that strategies other than literal borrowing (wordfor-word text) are being increasingly used by students to plagiarise. Sousa-Silva provides examples to illustrate why existing automated text-matching software may fail to detect these cases of plagiarism. The paper concludes that while text-matching software is able to detect literal, verbatim plagiarism, it should not necessarily be considered a good 'plagiarism detection system' particularly when other strategies are used, such as translation, word substitution or reordering. The author also reminds us of the need for manual analysis by a 'human detector' to ensure that any accusations of plagiarism take into account both the linguistic and educational complexity underlying textual similarities. Finally, Sousa-Silva calls for more research and improvements in computational linguistics and natural language processing to increase the accuracy and reliability of the machine-detection procedure.

In addition to the burgeoning international research on student plagiarism, Erja Moore, from Karelia University of Applied Sciences, Finland, suggests that accuracy of referencing might be another useful aspect to explore when examining students' writing practices. Moore analyses both the accuracy of referencing and plagiarism in 91 electronically published theses published in the Finnish Theseus database. In-text citations were compared to references, and in the case of frequent inaccuracy a Google search was used to scrutinise possible plagiarism. The accuracy of referencing was categorised into four classifications: accurate, some inaccuracy, constant inaccuracy and misleading referencing/plagiarism. Moore provides useful examples of inaccuracy, misquoting and plagiarism and also points to 'secondary source plagiarism', which occurs when text with accurate citations and references is copied from the original source and presented as the student's own.

The analysis in Moore's study indicated that nearly one third $(31 \%)$ of theses had major referencing inaccuracies, or referencing which could be categorised as misleading or plagiarised. It is clear from this study that constant inaccuracy and misleading referencing are categories that overlap with plagiarism. The results of Moore's study require careful consideration because they demonstrate that in Finnish higher education theses containing major inaccuracies have been accepted and published.

The title of the conference Plagiarism Across Europe and Beyond points to the widespread interest in the topic of plagiarism, well beyond Europe. Robert Craig and David Dalton, from the Petroleum Institute, Abu Dhabi, United Arab Emirates, investigated the perceptions of first-year students concerning the proportion and frequency of cheating among their peers, as well as the main reasons for cheating behaviour. Their findings demonstrated that at the start of the undergraduate programme, three quarters to four fifths of the students viewed copying as serious or very serious, but after only one semester this percentage had dropped considerably for some areas. The data established that there was a clear problem in need of a remedy.

The authors provide details of how the Communications Department of the Petroleum Institute facilitated a new, enquiry-based approach which facilitated student engagement, ownership and buy-in and which ultimately had a mitigating effect on copying and plagiarism. The authors make recommendations based on the experiences of their successful programme. In particular, they advocate for crossdepartmental collaboration, a consistent institutional voice on academic integrity, and curriculum based on experiential and enquiry-based learning.

Taking the lessons on academic integrity in the UK to countries outside Europe is the central theme in the final paper by Stephen Gow, University of York, UK. Gow's research was based on interviews with ten Mainland Chinese master's students who had studied at a UK university and then returned to work at joint-venture educational institution in Shanghai. Gow examined participants' accounts of plagiarism and 
compared and contrasted the experience of plagiarism in Chinese and British educational contexts. He anticipated that the study would uncover the extent to which returnee scholars transmit academic integrity and the concept of plagiarism when returning to work in transnational education in China.

The findings, using the qualitative methodology of interpretative repertoires, suggest that the participants used UK institutional vocabulary and developed a strict approach to plagiarism and academic integrity during their master's courses and in their subsequent educational careers. Furthermore, the participants in the study were able to "act as linguistic and cultural interpreters, promoting institutional relationships", despite some of the complexities of living, studying and working in two such different cultural and educational environments. Gow suggests that having moved between and adapting to these contexts, with appropriate support these returning Chinese graduates have the potential to act as a cultural bridge for academic integrity within internationalised higher education.

I trust you will discover new insights in this Special Issue of the International Journal for Educational Integrity as it provides a broad range of perspectives on academic integrity in the many contexts of Europe, and well beyond.

Tracey Bretag, IJEI Editor

June 2014 